\title{
Effect of organic loading rate on anaerobic digestion of pig manure: Methane production, mass flow, reactor scale and heating scenarios
}

Duan, Na; Zhang, Duojiao; Lin, Cong; Zhang, Yifeng; Zhao, Lingying; Liu, Hongbin; Liu, Zhidan

Published in:

Journal of Environmental Management

Link to article, DOI:

10.1016/j.jenvman.2018.10.062

Publication date:

2019

Document Version

Peer reviewed version

Link back to DTU Orbit

Citation (APA):

Duan, N., Zhang, D., Lin, C., Zhang, Y., Zhao, L., Liu, H., \& Liu, Z. (2019). Effect of organic loading rate on anaerobic digestion of pig manure: Methane production, mass flow, reactor scale and heating scenarios. Journal of Environmental Management, 231, 646-652. https://doi.org/10.1016/j.jenvman.2018.10.062

\section{General rights}

Copyright and moral rights for the publications made accessible in the public portal are retained by the authors and/or other copyright owners and it is a condition of accessing publications that users recognise and abide by the legal requirements associated with these rights.

- Users may download and print one copy of any publication from the public portal for the purpose of private study or research.

- You may not further distribute the material or use it for any profit-making activity or commercial gain

- You may freely distribute the URL identifying the publication in the public portal 
Environmental Management

Manuscript Number: JEMA-D-18-03867R1

Title: Effect of organic loading rate on anaerobic digestion of pig manure: methane production, mass flow, reactor scale and heating scenarios

Article Type: VSI:Biowaste and biomass

Keywords: anaerobic digestion; pig manure; organic loading rate; mass flow; biogas plant

Corresponding Author: Dr. Na Duan,

Corresponding Author's Institution: China Agricultural University

First Author: Na Duan

Order of Authors: Na Duan; Duojiao Zhang; Cong Lin; Yifeng Zhang;

Lingying Zhao; Hongbin Liu; Zhidan Liu 
Effect of organic loading rate on anaerobic digestion of pig manure: methane production, mass flow, reactor scale and heating scenarios

Na Duan ${ }^{1, *}$, Duojiao Zhang ${ }^{1}$, Cong Lin $^{1}$, Yifeng Zhang ${ }^{2}$, Lingying Zhao ${ }^{3}$, Hongbin Liu ${ }^{4, *}$, Zhidan Liu ${ }^{1}$ 1 Laboratory of Environment-Enhancing Energy (E2E), College of Water Resources and Civil Engineering, China Agricultural University, Beijing, 100083, China

2 Department of Environmental Engineering, Technical University of Denmark, Kgs.Lyngby DK-2800,

Denmark

3Department of Food, Agricultural and Biological Engineering, The Ohio State University, Columbus, OH 43210, USA

4 Key Laboratory of Nonpoint Source Pollution Control, Ministry of Agriculture/ Institute of Agricultural Resources and Regional Planning, Chinese Academy of Agricultural Sciences, Beijing, 100081, China

${ }^{*}$ Corresponding author.

Fax: +86-10-62737329; Tel: +86-10-62737329.

E-mail address: duanna @ cau.edu.cn (N. Duan).

Tel: $+86-10-8210-8763$

E-mail address: liuhongbin@ caas.cn (H.B. Liu) 
Abstract: The effect of organic loading rate (OLR) with total solid (TS) control $(3 \%-8 \%)$ on the performance of anaerobic digestion of pig manure (PM) using completely stirred anaerobic reactor was investigated. Based on the lab data, how OLR affects mass flow, construction scale and heating requirement in a farm-scale biogas plant was calculated. And three scenarios of typical reactor-heating technology were comparatively analyzed. The optimal OLR was $1.89 \mathrm{~g}$ volatile solid (VS) /(Ld) with methane yield of $438.38 \mathrm{~mL} / \mathrm{gVS}$ in the lab condition. The lower OLR, the larger amount of water and energy consumption, lower methane production and larger amount of liquid digestate was observed. Thus, the reactor with low OLR was suitable in tropical regions with the main target of disposing PM and fertilizer production. High OLR has advantage in the investment, but owns risk of instable process for a long-term run. In our study, among the three heating supply scenarios, biogas boiler was the best option for the designed biogas plant with the given breeding scale under moderate OLR. Combined heat and power (CHP) has potential advantage for the biogas plant under high OLR.

Key words: anaerobic digestion; pig manure; organic loading rate; mass flow; biogas plant 


\section{Dear Editor,}

I would hereby like to submit our manuscript entitled "Effect of organic loading rate on anaerobic digestion of pig manure: methane production, mass flow, reactor scale and heating scenarios" for possible publication in Journal of Environmental Management as an original research paper.

All authors have read and approved this version of the article, and all the authors mutually agree that it should be submitted to Journal of Environmental Management. The manuscript was not previously submitted to Journal of Environmental Management and no part of this paper has been published or submitted elsewhere. It is the original work of the authors. The language has been checked by a native tongue speaker with expertise in the field.

Important original contributions include the following:

- This work for the first time investigated how the effects of different OLRs on the mass flow and energy requirement observed in lab-scale operation are interpreted in large-scale without building a real large-scale reactor.

- Results showed that The optimal OLR was $1.89 \mathrm{gVS} /(\mathrm{L} . \mathrm{d})(5 \% \mathrm{TS})$ with high methane production and limited digestate production, stable process, moderate construction scale and cost, low operation cost and moderate self-heating energy compulsion. The reactor with low OLR was suitable in tropical regions with the main target of disposing PM and fertilizer production. High OLR has advantage in the investment, but owns risk of instable process for a long-term run. Among the three heating supply scenarios, biogas boiler was the best option for the biogas plant with the given breeding scale under moderate OLR. Combined heat and power (CHP) has potential advantage for the biogas plant under high OLR.

- This study may offer appropriate considerations for design of the commercial biogas plant The current manuscript consists of 5 figures and 3 tables.

We believe that the current study would be an interesting topic for Journal of Environmental Management readers. I look forward to receiving your evaluation.

Sincerely yours,

Na Duan

Ph.D, Associate Professor

College of Water Resources and Civil Engineering,

China Agricultural University, Beijing, 100083, China.

Tel: +86-10-6273-7329(O), Email: duanna@ cau.edu.cn 


\section{Dear Editor,}

Thanks for yours and reviewers' constructive comments on our manuscript entitled "Effect of organic loading rate on anaerobic digestion of pig manure: methane production, mass flow, reactor scale and heating scenarios" (Manuscript ID: JEMA-D-18-03867). We have carefully considered all comments and have made extensive revisions accordingly. Please find our detailed response and revisions as following; each change is marked in blue color.

\section{Responds to the reviewer's comments:}

\section{Reviewer \#1:}

The manuscript is of general interest; however, some important revisions are required before it can be considered for publication as follows:

1. There are plenty of grammatical and syntax errors throughout the manuscript which is a turn-off. Examples are, Page 5, L 11 "However, there is few studies linking...", P5, L15 "Thus, this is extreme important because ...", and many more. A thorough English revision is required. This is a Must should the paper be accepted for publication.

Answer: We have carefully polished the language in the revised manuscript.

2. Please include a photo of the experimental set-up used, a clear schematic presentation will also do.

Answer: Thanks for your constructive suggestion. I have added some information about the schematic of the reactor in the revised paper.

The schematic of the reactor was the same as previously described (Zhang et al., 2018). (Page 6, Line 21- Page 7, Line 1)

Zhang, D.J., Duan, N., Tian, H.L., Lin, C., Zhang, Y.L., Liu, Z.D., 2018. Comparing two enhancing methods for improving kitchen waste anaerobic digestion: Bentonite addition and autoclaved de-oiling pretreatment. Process Saf. Environ. 115, 116-124.

3. Please define abbreviations the first time they are used; Combined Heat and Power (CHP).

Answer: We have defined the abbreviation of CHP at the first time in the revised 
manuscript (Page 11, Line 4-5).

4. Please change "4. Conclusion" to "4. Conclusions".

Answer: We have changed "4. Conclusion" to "4. Conclusions" in the revised manuscript.

5. Please also report on the biochemical methane potential (BMP) of the substrate used. The following article should be used:

Jingura, R.M. and Kamusoko, R., 2017. Methods for determination of biomethane potential of feedstocks: a review. Biofuel Research Journal, 4(2), pp.573-586.

Answer: Thank you for your suggestion. We have calculated the biochemical methane potential using the method described in the literature as follows. We also added the results in the revised manuscript (Page 11, Line 12).

Jingura, R.M., Kamusoko, R., 2017. Methods for determination of biomethane potential of feedstocks: a review. Biofuel Res. J. 4(2), 573-586.

6. Three scenarios (i.e., solar energy, biogas boiler, and CHP) were analyzed and conclusions were drawn. However, the issue of sustainability has not been well discussed. Environmental sustainability is of utmost importance in the growing biofuel industry and should be included in the manuscript and discussed. The following articles should also be included and discussed:

Lynch, J.M., 2017. The Sustainability of Biofuels. Biofuels and Bioenergy, pp.261-272.

Rosen, M.A., 2018. Environmental sustainability tools in the biofuel industry. Biofuel Research Journal, 5(1), pp.751-752.

Ali, S., Xu, H., Al-amin, A.Q. and Ahmad, N., 2018. Energy sources choice and environmental sustainability disputes: an evolutional graph model approach. Quality \& Quantity, pp.1-21.

Answer: We have analyzed the sustainability and added the three references in the revised manuscript.

Sustainability is a vital factor while selecting the heat supply scenarios, which mainly include economic sustainability and environmental sustainability (Lynch, 2017). In terms of the economic cost, the investment of the biogas boiler, solar collector and electricity generator under $5 \%$ TS was about $\$ 0.63 \times 10^{4}, 1.88 \times 10^{5}$ and $3.14 \times 10^{5}$, respectively. Environmental sustainability has been widely investigated using 
different assessment methods, such as life cycle assessment, energy, exergy (Rosen, 2018). Specifically in energy system, energy production and utilization should avoid energy-environment conflict (Ali et al., 2018). Considering the environmental sustainability, the three scenarios are all have less environmental impact in comparison with heating using fossil energy. CHP has great conversion efficiency, thus, can achieve maximum greenhouse gases emission saving. However, the environmental costs caused by electricity generation using fossil fuel were often ignored, and the environmental benefits of electricity generation using biogas were also covered by its economic profit. Therefore the environmental value of electricity generation using biogas is not fully reflected and the technology competitiveness is not fully realized in China. Thereby, considering the energy efficiency and cost, biogas boiler was the best option for the biogas plant with the given breeding scale under moderate OLR. And the rest of the biogas can be used as domestic fuel for pig farms and neighboring households. However, for the CHP, because of the high efficiency and high profit from electricity, so in the long run, it may be a good choice for the biogas plant under high OLR. The solar collector can be used in tropical areas to enhance the heat availability and reduce the energy requirements, simultaneously reduce the collector areas and cost.

Lynch, J.M., 2017. The Sustainability of Biofuels, in: Love, J., Bryant, J.A. (Eds.), Biofuels and Bioenergy, John Wiley and Sons Ltd. UK, pp.261-272.

Rosen, M.A., 2018. Environmental sustainability tools in the biofuel industry. Biofuel Res. J. 5(1), 751-752.

Ali, S., Xu, H., Al-amin, A.Q., Ahmad, N., 2018. Energy sources choice and environmental sustainability disputes: an evolutional graph model approach. Qual. Quant. https://doi.org/10.1007/s11135-018-0775-9

\section{Reviewer \#2:}

1. The manuscript must be improved in terms of English language.

Answer: Thanks for your precious suggestion. We have carefully reviewed the language and clarity throughout the revised manuscript.

2. Abstract: "The effect of organic loading arte ..." Please mention here the OLRs you tested. It helps readers, who only read the introduction, to better understand what you are talking about.

Answer: We have revised the sentence as you suggested:

"The effect of organic loading rate (OLR) with total solid (TS) control (3\%-8\%) on 
the performance of anaerobic digestion of pig manure (PM) using completely stirred anaerobic reactor was investigated." (Page 2, Line 1-3)

3. Abstract: "how OLR affect mass flow, heating requirement and ..." should change to "how OLR affects ..."

Answer: We have written the sentence as you suggested:

"Based on the lab data, how OLR affects mass flow, construction scale and heating requirement in a farm-scale biogas plant was calculated." (Page 2, Line 3-5)

4. Abstract, Line 4: What do you mean by supply change here?

Answer: We have revised the sentence to make it clear.

"Based on the lab data, how OLR affects mass flow, construction scale and heating requirement in a farm-scale biogas plant was calculated. And three scenarios of typical reactor-heating technology were comparatively analyzed." (Page 2, Line 3-6)

5. Abstract: “... biogas boiler was the best option...”'It should be mentioned here this option is suitable for the plant you designed. A large number of researchers have already shown that CHP would be the best alternative in biogas plants because it can satisfy plant's heating requirement and simultaneously generate electricity which can substitute fossil based electricity.

Answer: A good suggestion. This point was proposed in this study, and we have rewritten this point as follow:

"In our study, among the three heating supply scenarios, biogas boiler was the best option for the designed biogas plant with the given breeding scale under moderate OLR."

6. Introduction needs to be rewritten to better present the idea behinds the work and the novelty of this research.

Answer: We have revised the introduction part in the revised manuscript, and two references added as follows:

Li, J., Kong, C.X., Duan, Q.W., Luo, T., Mei, Z.L., Lei, Y.H., 2015b. Mass flow and energy balance plus economic analysis of a full-scale biogas plant in the rice-wine-pig system. Bioresour. Technol.193, 62-67.

Dong, F.Q., Lu, J.B., 2013. Using solar energy to enhance biogas production from livestock residue-A case study of the Tongren biogas engineering pig farm in South 


\section{China. Energ. 57,759-765.}

7. Page 3 line 4 "However, most farms do not have adequate manure management measures to handle .." change to "However, most farms do not have adequate manure management strategies to handle .."

Answer: We have written the sentence as you suggested:

"However, most farms do not have adequate manure management strategies to handle the large amounts of manure and prevent environment pollution." (Page 3, Line 4-5)

8. Page 3 line 9: “... produce valuable by-products such as clean energy (biogas) and high-quality fertilizers ..." It depends on the substrate which is introduced to plant. For instance, if sludge or organic fraction of municipal solid waste are anaerobically digested the quiality of the digestate is a matter of issue.

Answer: We agree with you. The only substrate related in this study is animal manure; we do not have sludge or any other organic fraction of municipal solid waste. A large number of researchers have already shown that the digestate from animal manure AD system can be used as fertilizers.

10. Table 1. Some important parameters can be added to this table. For example how much were Total $\mathrm{N}$ and total ammonium nitrogen?

Answer: We have added the total Kjeldahl nitrogen (TKN) in Table 1. We did not measure the ammonium nitrogen of the substrate. However, we measured the ammonium nitrogen of the digestate in the AD process.

11. Page 6, line 13. Do you have Characteristics of inoculum? It can be added to Table 1.

Answer: A good suggestion. We have added the characteristics of inoculum in Table 1 .

12. Page 6, line 20. Did you sieve PM before feeding the reactor?

Answer: We did not sieve the PM before feeding the reactor. Because we did not use pump to feed, we just feed manually.

13. Page 7, line 9: ' by multiplying the organic nitrogen by $6.25^{\prime}$. Please check this coefficient in the literature. It must be 0,625

Answer: We have checked the related literature. The coefficient is 6.25. 
14. Section 2,3. Analytical method. Many parameters like TKN, COD, Trace elements, etc have been mentioned here but they have not been presented in the manuscript? Please provide such information in proper places within the text or tables.

Answer: We have measured TKN, lipids, crude fibers and element for the raw material (pig manure), and all the data has been listed in Table 1. We measured TCOD, SCOD and total ammonia concentration in the AD process. All the data has been stated in Fig.2 and Fig. 3. The analysis of the data was in the section of 3.1.2 and 3.1.3.

15. Eq.1. When you use TAN (total ammonium nitrogen NH4-N) you will have free ammonia nitrogen(NH3-N) and not free ammonia. Please correct it in the equation.

Answer: We have revised equation in the revised manuscript.

16. Page 9 line 1. Change 'Heat losses' to 'Heat is lost ...'

Answer: We have written the sentence as you suggested:

"Heat is lost through the biogas, the reactor and evaporation, which may increase the heat consumptions " (Page 9, Line 6-7)

17. Table 2. ' $\mathrm{CH}_{4}$ production $(\mathrm{mL} / \mathrm{gVS})$ ' can be replaced by the term 'Specific methane yield $(\mathrm{mL} / \mathrm{gVS})^{\prime}$.

Answer: We have used "Specific methane yield (mL/gVS)" replacing " $\mathrm{CH}_{4}$ production (mL/gVS)" in Table 2 .

18. Page 11 line 13. "The maximum methane yield ..." this comparison is not correct. First of all, your substrate was PM while those referenced were swichgrass and pig slurry. On the other hand, all VS cannot change to biogas and it depends on the degradability of the substrate. For instance wheat straw has a high VS but due to its rigid structure it cannot be degraded without pretreatment. If the yield was expressed based on COD, the comparison would make sense.

Answer: Thanks for your suggestion. In general, when we compared the methane yield with different treatments or literatures, methane yield based on VS or COD are used. In this study, we will use the lab-experiment data to investigate how would be the effects of OLR on AD process performance in large-scale biogas plant. For large-scale biogas plant, VS is very easier than COD to measure. Thus, in present study, methane yield based on VS was used to compare with different treatments and 
other literature.

19. Page 12 line 2. "Thus, the incomplete degradation and overload inhibited ..." Please show the total VFA and $\mathrm{pH}$ changes in one graph. The selected OLRs were not so high that can cause inhibition. This graph can show VFA changes and $\mathrm{pH}$ changes during the experiment to see if any inhibition was occurred.

Answer: Thanks for your precious comment. We understand that VFA is an important index for anaerobic digestion. Although the VFA was not analyzed in this study, comparative analysis of other important parameters including ammonia, biogas production and composition, as well as organic matter reduction during the AD process have been studied. So that we can synthetically assess the AD performance through the above mentioned parameters

20. Page 13 line 6. In this study OLR was set by changing the TS of the substrate. When TS of the substrate increases, it is clear that the total $\mathrm{N}$ in the substrate increases also. Therefore, we expect to have higher TAN in the digestate but the TAN and FAN presented in the Figure 3 do not show any sign of inhibition. Specially, your reactors worked under mesophilic condition and under such circumstances the risk of free ammonia inhibition is lower. I suggest to present the TAN and FAN of the substrate and digestate. It helps reader to better understand what has happened in your reactors.

Answer: Thanks for your suggestion. As shown in Table 1, we have added the TAN of the inoculum and the TKN of the PM. Although the TAN and FAN of the PM was not analyzed in this study, the change of TAN and FAN in the whole process has been evaluated. Thereby the reader can obtain the changing trend of TAN and FAN concentration in the whole process with different OLRs.

21. Page 15 line 9. "Specifically, the total ..." It is not clear why energy consumption of $3 \% \mathrm{TS}$ was higher than others.

Answer: The conclusion can be obtained from Table 3. Table 3 has listed the heat requirements of different OLRs. The lower OLR, the larger amount of water consumption and liquid diegstate, as well as larger reactor volume was observed. Thereby, more energy will be consumed at $3 \%$ TS. 


\section{Highlights}

1. How organic loading rate affect anaerobic digestion of pig manure.

2. The optimal organic loading rate of pig manure was $1.89 \mathrm{gVS} / \mathrm{L} . \mathrm{d}(5 \% \mathrm{TS})$.

3. Organic loading rate has significantly affected mass flow and heating requirement.

4. Different heating supply scenarios have been comparatively analyzed.

5. Low organic loading rate was suitable for operation in tropical regions. 
1 Effect of organic loading rate on anaerobic digestion of pig manure: methane production, mass flow, reactor scale and heating scenarios

3 Na Duan ${ }^{1, *}$, Duojiao Zhang ${ }^{1}$, Cong Lin $^{1}$, Yifeng Zhang ${ }^{2}$, Lingying Zhao ${ }^{3}$, Hongbin Liu ${ }^{4, *}$, Zhidan Liu ${ }^{1}$

1 Laboratory of Environment-Enhancing Energy (E2E), College of Water Resources and Civil

62 Department of Environmental Engineering, Technical University of Denmark, Kgs.Lyngby DK-2800,

Denmark

3Department of Food, Agricultural and Biological Engineering, The Ohio State University, Columbus,

104 Key Laboratory of Nonpoint Source Pollution Control, Ministry of Agriculture/ Institute of Agricultural

11 Resources and Regional Planning, Chinese Academy of Agricultural Sciences, Beijing, 100081, China

* Corresponding author.

14 Fax: +86-10-62737329; Tel: +86-10-62737329.

15 E-mail address: duanna@cau.edu.cn (N. Duan).

16 Tel: +86-10-8210-8763

17 E-mail address: liuhongbin@caas.cn (H.B. Liu) 
1 Abstract: The effect of organic loading rate (OLR) with total solid (TS) control

$2(3 \%-8 \%)$ on the performance of anaerobic digestion of pig manure (PM) using

3 completely stirred anaerobic reactor was investigated. Based on the lab data, how OLR

4 affects mass flow, construction scale and heating requirement in a farm-scale biogas

5 plant was calculated. And three scenarios of typical reactor-heating technology were

6 comparatively analyzed. The optimal OLR was $1.89 \mathrm{~g}$ volatile solid (VS) /(Ld) with

7 methane yield of $438.38 \mathrm{~mL} / \mathrm{gVS}$ in the lab condition. The lower OLR, the larger

8 amount of water and energy consumption, lower methane production and larger amount

9 of liquid digestate was observed. Thus, the reactor with low OLR was suitable in

10 tropical regions with the main target of disposing PM and fertilizer production. High

11 OLR has advantage in the investment, but owns risk of instable process for a long-term

12 run. In our study, among the three heating supply scenarios, biogas boiler was the best

13 option for the designed biogas plant with the given breeding scale under moderate OLR.

14 Combined heat and power (CHP) has potential advantage for the biogas plant under

15 high OLR.

16 Key words: anaerobic digestion; pig manure; organic loading rate; mass flow; biogas

17 plant 


\section{Introduction}

2 In China, the manure quantities increase rapidly in a few concentrated areas as a

3 result of large-scale and intensive livestock production moving towards (Deng et al.,

4 2017). However, most farms do not have adequate manure management strategies to

5 handle the large amounts of manure and prevent environment pollution (Jiang et al.,

6 2011). In response to the problem, the Chinese government has implemented a series of

7 management and incentive policies. All these regulations recognize that biogas

8 technology is an environment-friendly solution to reduce environmental pollutions and

9 produce valuable by-products, such as clean energy (biogas) and high-quality fertilizers.

10 Besides, because of the reliability of anaerobic digestion (AD) technology and growing

11 awareness of environmental protection from farm owners, the number of large- and

12 medium-scaled biogas plants built in livestock farms increases with the average annual

13 growth rate of about $9.15 \%$ from 2001 to 2006 and $21.53 \%$ from 2006 to 2010 (Yang et

14 al., 2012). In China, nearly more than $90 \%$ of the biogas plants are built up for manure

15 management (MOA, 2011). Particularly, China is rich in resource of pig manure (PM)

16 with pig rearing amount of 465 million heads in 2014 (Yu et al., 2015), thereby, due to

17 its abundance, inherent buffering and containing a wide range of nutrients for the

18 growth of anaerobic microorganisms, PM has a great potential for scaled biogas

19 generation (Regueiro et al., 2012). In addition, a variety of anaerobic reactors have been

20 developed and applied in China including continuous stirred tank reactor (CSTR),

21 up-flow anaerobic sludge blanket (UASB), up-flow solids reactor (USR), and plug flow 
1 reactor (PFR). Among which, the biogas plants with CSTR and USR technologies are

2 prominent, comprising $65 \%$ of the total plants (Chen et al., 2012).

3 The $\mathrm{AD}$ process is complex, affected by many factors including the type and

4 composition of the substrate, microbial composition, temperature, organic loading rate

5 (OLR), $\mathrm{pH}$ and reactor configuration, etc. Many studies have reported that temperature

6 is one of the most crucial factors influencing the microbial community, process kinetics,

7 stability, substrate utilization rates, and methane yield (Bouallagui et al., 2009;

8 Dela-Rubia et al., 2002; Riau et al., 2010). The AD process is commonly operated in the

9 mesophilic temperature, considering the process stability, energy expense and

10 microorganism sensitivity (El-Mashad et al., 2003; Fernandez et al., 2008; Ward et al.,

11 2008).

12 OLR is also considered as an important operational parameter. The high OLR means

13 high treatment capacity and methane yield, but it also may lead to overloading and

14 thereby causing process instability, and even system failure. Li et al. (2015a) reported

15 operating limits of OLR when livestock manure was mono-digested. Guo et al. (2013a)

16 indicated that there might be a risk of acidification if the reactor operated below $38{ }^{\circ} \mathrm{C}$ at

17 high OLRs. Thus, there is a need for a strategy to find a suitable OLR for achieving a

stable and optimum anaerobic digestion of pig manure.

19 Regarding PM, its carbon to nitrogen $(\mathrm{C} / \mathrm{N})$ ratio was lower relative to the optimum

$20 \mathrm{C} / \mathrm{N}$ ratio (20:1-30:1) existing ammonium inhibition risk. Therefore, several studies, in

21 batch or continuous experiments, have indicated the benefits of co-digestion with other 
1 wastes (Astals et al., 2013; Ren et al., 2014; Zhang et al., 2014), however, PM is still

2 commonly used as the sole feedstock to produce biogas for most farms in China.

3 Actually, for co-digestion, the sources, transportation, and supply stability of the

4 co-substances should be considered to keep a long run of the biogas plant.

5 Some existing biogas plants have been operating at low efficiency owing to various

6 technical barriers, such as running at lower or higher OLR, fluctuant digestion

7 temperature, lack of knowledge about maintenance and monitoring, etc.(Deng et al.,

8 2017). Thus, the appropriate operating conditions are essential for the commercial and

9 sustainable development of $\mathrm{AD}$ technology treating PM. Most of the AD studies are in

10 lab-scale (Guo et al., 2013a; Ni et al., 2017; Tsapekos et al., 2017) or evaluat the

11 operational performance of existed biogas plants (Dong and Lu, 2013; Li, et al., 2015b).

12 The results and discussion from lab-scale indeed could provide insight into large-scale

13 development. However, there are few studies linking the data from lab-scale to give

14 design consideration for a farm-scale biogas plant, in particular, how the effects of

15 different OLRs on the mass flow and energy requirement observed in lab-scale

16 operation be interpreted in large-scale without building a real large-scale reactor has

17 never been investigated. Thus, this is extremely important because it can (i) help to

18 know the input, output and detailed mass flow and energy consumption, (ii) investigate

19 different scenarios to provide appropriate considerations for the design of the

20 commercial biogas plant.

21 In the present study, anaerobic digestion of PM was performed with different OLRs 
1 operation using total solid (TS) control $(3 \%-8 \%)$ at mesophilic temperature $\left(35 \pm 1^{\circ} \mathrm{C}\right)$ in

2 lab-scale. The data obtained was then used as input for validating the results in

3 large-scale. The objective is to: (1) investigate how would be the effects of OLR on AD

4 process performance in large-scale based on the simple modeling; (2) simulate the

5 variations of mass flow, biogas plant scale and heating requirement under different

$6 \mathrm{OLR}_{\mathrm{S}}$ in large-scale using lab-scale data. (3) analyze different scenarios of heat supply

7 and sustainability.

$8 \quad 2$ Materials and methods

$9 \quad 2.1$ Feedstock and inoculum

10 The fresh PM as the substrate for the biogas production was collected from

11 Beilangzhong pig farm (Shunyi District, Beijing, China), and then was delivered to the

12 laboratory and stored at $4^{\circ} \mathrm{C}$ until use. The PM had a high proportion of carbohydrates

13 (over 60\% TS), followed by the crude protein and crude lipids. The $\mathrm{C} / \mathrm{N}$ ratio was

14 approximate 10.64. The inoculum was obtained from a centralized biogas plant treating

15 PM anaerobically and inoculated with PM for two weeks prior to use. The

16 characteristics of the PM and inoculum are presented in Table 1.

\section{$17 \quad 2.2$ Reactors and experimental set-up}

18 Six identical 20-L semi-continuous stirred-tank reactors (CSTR) with a working

19 volume of 17.5-L were used. Reactors were operated under a mesophilic condition at

$2035 \pm 1{ }^{\circ} \mathrm{C}$ by circulating water from a heated water bath (SY-200, Changfeng Yi Qi Yi

21 Biao Company, Beijing, China) through a water jacket surrounding the reactor. The 
1 schematic of the reactor was the same as previously described (Zhang et al., 2018). The

2 reactors (R1-R6) were manually fed once per day with TS concentration of $3 \%$ to $8 \%$,

3 while their OLRs were set at 1.13 to $3.03 \mathrm{gVS} / \mathrm{Ld}$ (Table 2). The PM was diluted with

4 tap water to the target feeding loads and an equivalent volume of digestate was purged

5 once a day. The reactor was stirred at $60 \mathrm{rpm}$ and the hydraulic retention time (HRT)

6 was set at 22 days. Each reactor was generally operated for nearly 2 HRTs reaching a

7 steady state with stable daily methane yield, $\mathrm{pH}$ and COD removal.

\section{$8 \quad 2.3$ Analytical methods}

9 Total Kjeldahl Nitrogen (TKN), lipids and crude fibers were measured following the

10 standard procedure of Kjeldahl method, Soxhlet method and cellulose analyzer (Model

11 A220, ANKOM Technology Corporation, NY, USA), receptively. Protein was estimated

12 by multiplying the organic nitrogen by 6.25 and carbohydrates were estimated by

13 subtracting the amount of protein and lipids from volatile solids. Elemental analysis was

14 conducted using an element analyzer (Vario MICRO Cube, Elementar Analysen

15 systeme GmbH, Donaustraße, Germany).

16 The biogas yield was automatically measured using a gas flow meter (LML-1,

17 Changchun Automotive Filter Co., LTD, Changchun, China) and biogas composition

18 was analyzed every day using the gas chromatograph (Model 1400, Agilent

19 Technologies, USA). The biochemical methane potential was calculated based upon the

20 main organic compositions as described (Jingura and Kamusoko, 2017). Digestate

21 samples were collected from the reactors every three days. The TS, VS, total chemical 
1 oxygen demand (TCOD), soluble chemical oxygen demand (SCOD) concentration and

2 total ammonia nitrogen (TAN) concentration were determined following the guidelines

3 given by the standard methods (APHA, 2005). The free ammonia nitrogen (FAN)

4 concentration was calculated based on TAN concentration and experimental conditions

5 including temperature and pH using the following Eq.(1) (Hansen et al., 1998):



6

where FAN is the concentration of free ammonia nitrogen in $\mathrm{mg} / \mathrm{L}$, TAN is the total ammonia nitrogen concentration in $\mathrm{mg} / \mathrm{L}, \mathrm{pH}$ is the $\mathrm{pH}$ value determined in the reactor, and $\mathrm{T}(\mathrm{k})$ is the temperature (Kelvin).

\subsection{Mass flow calculation}

In order to investigate the effects of OLR on the mass flow and construction scale for a commercial biogas plant, a hypothesized process of a pig farm with 5000 pigs annually on hand in Beijing of China and the annual manure treatment capacity of $2920 \mathrm{t}$ (collection coefficient of 80\%) was used for calculation. Typically, a commercial biogas plant consists of different subsystems. The pre-treatment tank, anaerobic reactor and digestate storage tank are the principal facilities, and their volumes can be calculated based on the targeted OLR, HRT and storage time. Based on the lab-scale data, the mass

flow and total solid flow of three major components (pre-treatment, anaerobic digestion,

by-products utilization) of biogas plant under different OLRs were calculated.

\subsection{Heating requirement and supply scenarios}


1 The optimal and economical temperature for biogas production is around $35{ }^{\circ} \mathrm{C}$,

2 thereby, the biogas plant requires external heating to stabilize at the mesophilic range in

3 moderate and cold climates. Besides that, the heating requirement also depends on the

4 OLR and reactor volume. There are two heat demands in the farm-scale biogas plant,

5 one is for preheating the influent in the pre-treatment tank and the other is for

6 maintaining normal digestion temperature in the $\mathrm{AD}$ reactor. Heat is lost through the

7 biogas, the reactor and evaporation, which may increase the heat consumptions. The

8 total heating requirements were illustrated in Fig.1 and the heating requirement in

$9 \quad$ winter was calculated using Eq.(2).

$10 \quad \sum Q=Q_{1}+Q_{2}+Q_{3}+Q_{4}+Q_{5}$

11 where $\sum \mathrm{Q}$ is total heating requirement of the farm-scale biogas plant $(\mathrm{MJ} / \mathrm{d})$; the

12 definition of the $\mathrm{Q}_{1}, \mathrm{Q}_{2}, \mathrm{Q}_{3}, \mathrm{Q}_{4}, \mathrm{Q}_{5}$ has been stated in Fig.1.

$13 \quad Q_{1}=c m_{1}\left(T_{1}-T_{a}\right)$

14 where $\mathrm{c}$ is the average specific heat of the influent $\left(4.17 \mathrm{~kJ} /\left(\mathrm{kg}^{.0} \mathrm{C}\right)\right) ; \mathrm{m}_{1}$ is the weight

15 of the daily feeding influent $(\mathrm{kg}) ; \mathrm{T}_{1}$ is the heating temperature (considering the heat 16 loss in the heating process, $\mathrm{T}_{1}\left(38{ }^{\circ} \mathrm{C}\right)$ should be higher than the desired 17 temperature $\left.\left(35^{\circ} \mathrm{C}\right)\right) ; \mathrm{T}_{\mathrm{a}}$ is the ambient temperature of Beijing in winter $\left({ }^{\circ} \mathrm{C}\right)$.

$18 \quad \mathrm{Q}_{2}$ can be calculated as Eq.(4) to keep the temperature fluctuation of $1{ }^{\circ} \mathrm{C}$.

$19 \mathrm{Q}_{2}=c \rho V \Delta t$

20 where $\rho$ is the density of the digestate in the anaerobic reactor $\left(1.04 \mathrm{t} / \mathrm{m}^{3}\right) ; \mathrm{V}$ is the 21 effective volume of the anaerobic reactor $\left(\mathrm{m}^{3}\right) ; \Delta \mathrm{t}$ is the temperature fluctuation of $1{ }^{\circ} \mathrm{C}$. 
$1 \quad \mathrm{Q}_{3}$ can be calculated by Eq. (5) (Guo et al., 2013b).

$$
Q_{3}=\left(1676+1772 \cdot \frac{1-f}{f}\right)(V \cdot \gamma)\left(T-T_{\ltimes}\right)
$$

3 where $f$ is the methane content $(\%) ; \gamma$ is the volumetric methane production $4 \quad\left(\mathrm{~m}^{3} \mathrm{CH}_{4} / \mathrm{m}^{3} / \mathrm{d}\right) ; \mathrm{T}$ is the fermentation temperature $\left(35^{\circ} \mathrm{C}\right)$.

$5 \quad \mathrm{Q}_{4}$ can be calculated as Eq. (6) (Guo et al., 2013b).

$6 \quad Q_{4}=W_{\omega} \cdot\left[H_{V}+C_{V} \cdot\left(T-T_{\varepsilon}\right)\right]$

7 where $\mathrm{W}_{\omega}$ is the mass flow rate of vapor from anaerobic reactor $(\mathrm{kg} / \mathrm{d}) ; \mathrm{H}_{\mathrm{v}}$ is latent 8 heat of vaporization $\left(2415 \mathrm{~kJ} / \mathrm{kg}\right.$ at $\left.35^{\circ} \mathrm{C}\right) ; \mathrm{C}_{\mathrm{v}}$ is the specific heat of vapor $(1.886 \mathrm{~kJ} /(\mathrm{kg}$ '

$\left.9 \quad{ }^{\circ} \mathrm{C}\right)$ ). $\mathrm{W}_{\omega}$ can be calculated as Eq. (7) and (8) (Guo et al., 2013b).$$
W_{\omega \omega}=0.804 \times \frac{V \cdot \gamma \cdot X_{\omega}}{f\left(1-X_{\omega \omega}\right)}
$$

$X_{\omega}=1.27 \times 10^{6} e^{\frac{-5520}{5+273}}$

$12 \mathrm{Q}_{5}$ can be calculated according to the heat transfer theory as Eq. (9).

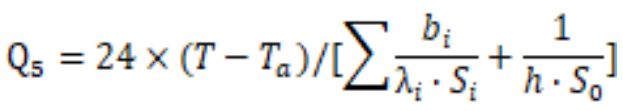

14 where the $b_{i}$ is the thickness of the reactor base, enameled steel and insulation

15 material (Extruded polystyrene) about $0.5 \mathrm{~m}, 0.08 \mathrm{~m}$ and $0.1 \mathrm{~m}$, respectively. The thermal

16 conductivity $\left(\lambda_{i}\right)$ of the reinforced concrete, insulation material and enameled steel is 1.3 ,

170.033 and $2.05 \mathrm{~W} / \mathrm{m}^{.0} \mathrm{C}$, respectively (Pu et al., 2010). $\mathrm{S}_{\mathrm{i}}$ is the area of the reactor bottom,

18 wall and top $\left(\mathrm{m}^{2}\right)$, and $\mathrm{S}_{0}$ is the surface area of the reactor $\left(\mathrm{m}^{2}\right)$. The height and the

19 diameter of the anaerobic reactor should be assumed according to the lab experiment 
1 results to calculate the $S_{i}$ and $S_{0}$. The heat exchange coefficient of the environment is

$2 \quad 23 \mathrm{~W} /\left(\mathrm{m}^{2.0} \mathrm{C}\right)$ (Liu et al., 2012).

3 Based on the total heating requirements in winter, three scenarios of typical

4 digester-warming technologies including biogas boiler, solar energy, combinedd heat

5 and power (CHP) were analyzed to evaluate their energy efficiencies and economic

6 cost.

$7 \quad 3$ Results and discussions

$8 \quad 3.1$ Process performance of the lab-scale experiment

\section{$9 \quad$ 3.1.1 Methane production}

10 The results of the present study demonstrated that OLR had a great effect on methane

11 production (Table 2). As the OLR increased, methane yields were varied (324.25-

$12438.38 \mathrm{~mL} / \mathrm{gVS}$ ) corresponding to more than $73 \%$ of the theoretical maximum and not

13 linear within the tested range. The maximum methane yield was achieved at the OLR of

$14 \quad 1.89 \mathrm{gVS} / \mathrm{L}$ d (5\%TS), which was $11.81 \%$ and $35.20 \%$ higher than that with the lower

15 OLR (1.13 gVS/Ld, 3\% TS) and higher OLR (3.03gVS/Ld, 8\% TS), respectively. As the

16 OLR increased from 1.89 to $3.03 \mathrm{gVS} / \mathrm{Ld}$, a decrease in methane production was

17 observed, this was expected due to the incomplete degradation with a high level of

18 feeding OLRs. Consequently, the optimal OLR of PM was found to be $1.89 \mathrm{gVS} / \mathrm{Ld}$

19 (5\%TS) under mesophilic conditions with HRT of 22 days.

20 The maximum methane yield, $438.38 \mathrm{~mL} / \mathrm{gVS}$, is relatively higher compared to that 21 normally can be achieved, i.e.220-350 mL/gVS from PM (Ahn et al., 2009; Bonmati et 
1 al., 2001) and comparable to the results of Chae et al. (2008) about $437 \mathrm{~mL} / \mathrm{gVS}$ at 35

$2 \quad{ }^{\circ} \mathrm{C}$ with the feeding load of $5 \% \mathrm{TS}$. The varying methane yields are due to the different

3 chemical compositions of the $\mathrm{PM}$ and the $\mathrm{AD}$ operation process.

4

\subsubsection{Organic matter reduction}

As the OLR increased, the TCOD of the feeding, as well as the TS and VS content of the digestate increased obviously (Table 2 and Fig. 2A). The values of TS and VS removal at the steady stage were in the range of $53.25-57.43 \%$ and $59.61-66.22 \%$, respectively. Similarly, SCOD concentrations of digestate increased with the increasing OLR. Thus, the incomplete degradation and overload inhibited the activity of methanogenic bacteria, which might occur in the reactors with higher OLRs (R5 and R6). The Values for TCOD reduction were in the range of $67.40-76.18 \%$, and the SCOD removal was all over $80 \%$ (Fig.2B). Compared with higher or lower OLR, the reactors with moderate $\mathrm{OLR}_{\mathrm{S}}$ had a more stable methane production and organic matter reduction, and the highest removal of TS (57.43\%), VS (66.22\%), TCOD (76.18\%) and SCOD (89.99\%) was obtained under the OLR of $1.89 \mathrm{gVS} /(\mathrm{Ld})(5 \% \mathrm{TS})$.

All the reactors obtained a $\mathrm{BOD}_{5}$ removal with a range of $74 \%-86 \%$ (Table 2). These results indicate all of the reactors had a high conversion capacity of organic waste and operating efficiency.

\subsection{3 pH and ammonia}

The initial $\mathrm{pH}$ value of the six reactors was 7.21 and the good digestion environment gives a buffering capacity for the feeding substrate. Thus, a stable $\mathrm{pH}$ for R1-R6 was 
$17.19 \pm 0.14,7.27 \pm 0.05,7.32 \pm 0.06,7.39 \pm 0.05,7.42 \pm 0.05$ and $7.45 \pm 0.08$, respectively. Liu

2 et al. (2008) showed that the most favorable range of $\mathrm{pH}$ to attain maximal biogas yield

3 is 6.5-7.5. As the OLR increased, the $\mathrm{pH}$ values always showed an upward trend,

4 particularly for R5 and R6. This was because of the phenomena that the higher OLR

5 resulted in the higher TAN and FAN concentration (Fig.3). Therefore, careful

6 consideration was required when increasing the OLR for the purpose of enhancing the

7 methane yield due to the simultaneous increase of the risk of ammonia inhibition.

$8 \quad \mathrm{PM}$ is protein-rich material, thus, TAN and FAN coming from proteins breakdown are

9 the foremost inhibitors to the $\mathrm{AD}$ process if they are available at high concentrations

10 (Yenigün and Demirel, 2013). Ammonia inhibition occurred in the range of 1500-3000

$11 \mathrm{mg} / \mathrm{L}$ TAN with $\mathrm{pH}$ above 7.4 , and if the TAN concentration was over $3 \mathrm{~g} / \mathrm{L}$, ammonia

12 was claimed to be toxic irrespective of pH (Abouelenien et al., 2010; Calli et al., 2005).

13 In this study, the TAN concentration of R1-R3 was always below $1500 \mathrm{mg} / \mathrm{L}$ (Fig.3A).

14 However, with the increase of OLRs, the TAN concentration increased to nearly

$152500 \mathrm{mg} / \mathrm{L}$ in R6 with an average $\mathrm{pH}$ value of 7.45 (Fig.3A and Table 2), which was

16 within the inhibitory range. In addition, FAN concentrations ranging from 80 to 150

$17 \mathrm{mg} / \mathrm{L}$ have shown an inhibition of the AD process (Yenigün and Demirel, 2013). The

18 increased OLR resulted in the rising FAN concentration, especially the FAN

19 concentration more than $90 \mathrm{mg} / \mathrm{L}$ at OLR of $3.03 \mathrm{gVS} /(\mathrm{Ld})(8 \% \mathrm{TS})(\mathrm{Fig} .3 \mathrm{~B})$. Thus, the

20 lower methane yields obtained in higher OLRs may have been a consequence of the high TAN and FAN concentration. It was concluded that the reactors were successfully 
1 operated without inhibition and showed stable and high-efficiency operation under the

2 feeding TS concentration of $5 \%$.

$3 \quad 3.2$ Simulation study of how OLR affect system performance in large-scale

$4 \quad$ 3.2.1 Mass flow and construction scale

5 The feeding amount and construction scale of biogas plant could be significantly

6 affected by the varying OLRs (Fig 4). Specifically, $8.0 \mathrm{t} / \mathrm{d}$ of fresh PM and a certain

7 amount of additional water were preheated and mixed in the pre-treatment tank. With

8 the increasing OLR, water consumption amount reduced by $28.58 \%, 45.73 \%, 57.16 \%$,

$9 \quad 65.33 \%$ and $71.46 \%$ from $3 \%$ TS to $4-8 \% \mathrm{TS}$, respectively. After fermentation and

10 solid-liquid separation, about $97.37 \%, 95.40 \%, 93.50 \%, 92.00 \%, 89.87 \%$ and $88.01 \%$

11 of the total mass made their way to the liquid digestate of $3 \% \mathrm{TS}$ to $8 \% \mathrm{TS}$, respectively,

12 1.66-3.84\% became biogas and $0.97-8.15 \%$ turned into solid digestate. In addition,

13 about $53-57 \%$ of total TS (1.02-1.10t/d) transferred into biogas, $11-36 \%$ and $11-33 \%$

14 turned into solid and liquid digestate, respectively.

15 With respect to the construction scale, the pre-treatment tank was designed for storing 16 at least two-day feeding. The effective volume of anaerobic digester was determined as

17 sufficient with a $15 \%$ safe vacant according to the HRT, feeding loads and physical

18 characteristics of PM. Considering the digestate amount and seasonal agricultural

19 application, digestate storage tank should have enough space for storing digestate over

20 three months. Compared with OLR of 3\%TS, the volume of pre-treatment tank, CSTR

21 reactor and digestate storage tank decreased by nearly $28 \%, 42 \%, 52 \%, 59 \%$ and $64 \%$, 
1 while OLR increased to $4 \% \mathrm{TS}-8 \% \mathrm{TS}$, respectively. The lower OLR, the larger amount

2 of water consumption and liquid diegstate, as well as larger reactor volume was

3 observed, which implied the higher initial investment and larger covering space.

4 Conversely, only from the perspective of construction investment, higher OLR poses

5 huge advantages. However, considering the long-term running, the OLR affected the

6 feeding composition and degradation efficiency (Igoni et al., 2008), the higher OLR

7 (like 8\%) had great risk of unstable process and ammonia inhibition found in our study

8 (Fig.2) and other previous studies (Guo et al., 2013a; Li et al., 2015; Li et al., 2018).

9 Some attempts have been made to solve the problem, like co-digestion, using additives

10 (Tada et al., 2005) or separating the pig slurry into different concentration fractions

11 (Deng et al., 2014). Nevertheless, the extra operating cost during this process needed to

12 be considered for a long-term run.

\subsubsection{Effects of OLR on the heating requirement and supply scenarios}

14 Based on the volume of the anaerobic reactor, the height and diameter of the reactor

15 were assumed according to its volume (Table 3). The OLR was considered to be a key

16 parameter that influenced the self-heating requirement. Specifically, the total energy

17 consumption of $3 \% \mathrm{TS}$ was $1.33,1.66,2.34,2.81$ and 3.31 times of that with OLR of

$184 \% \mathrm{TS}$ to $8 \% \mathrm{TS}$ (Table 3). And the biogas needed to afford the heating energy decreased

19 from $712.27 \mathrm{~m}^{3}$ to $215.18 \mathrm{~m}^{3}$ while the OLR increasing from $3 \% \mathrm{TS}$ to $8 \% \mathrm{TS}$ (no heat

20 loss is considered). When the OLR was lower than 5\% TS, over 50\% of the produced

21 biogas will be used for self-heating. However, irrespective of different OLRs, the 
1 energy consumption for heating the feeding and maintaining digestion temperature

2 accounted for a large proportion of over $97 \%$, and heat loss only took up less than $3 \%$.

3 In addition, OLR also could influence the proportion of different heating requirements.

4 While the OLR lower than 5\%TS, the Q1 value was higher than 60\%, otherwise, the

5 value was lower than 50\% at high OLR. For the low OLR, the large reactor volume and

6 feeding amount resulted in a large amount of self-heating energy and operation cost. In

7 fact, it is difficult to increase the digestion temperature for the reactor running at low

8 OLR (Deng et al., 2017). Thus, it is adaptable to run in tropical regions with the main

9 target of solving the problems of PM disposal and utilizing biogas digestate as fertilizer,

10 instead of producing biogas. Conversely, for the high OLR, the balance between the

11 investment cost and the stable operation cost for a long-term run should be estimated.

12 Thereby, considering the running process and operational cost, the OLR of about 5\%TS

13 was more advanced in the following aspects: high methane production and limited

14 digestate production, stable process, moderate construction scale and cost, low

15 operation cost and moderate self-heating energy compulsion.

16 According to the daily biogas production and the daily energy demand, three

17 scenarios (solar energy, biogas boiler and CHP) of reactor-heating technology was analyzed under 3\%, 5\% and 8\%TS. (Fig.5)

19 Scenario 1: solar energy. The maximum and minimum monthly average solar

20 radiation of Beijing district was occurred in May and December respectively, with its 21 average solar radiation of $21.35 \mathrm{MJ} /\left(\mathrm{m}^{2} \cdot \mathrm{d}\right.$ ) and $7.45 \mathrm{MJ} /\left(\mathrm{m}^{2} \cdot \mathrm{d}\right.$ ) (Zhou et al., 2005). As we 
1 can see from Fig.5A, because of the low solar radiation in winter of Beijing, an

2 enormous solar thermal collector (nearly $2000 \mathrm{~m}^{2}$ with the heat loss of $10 \%$ ) was needed

3 at low OLR of 3\%TS. When the OLR increased to 5\%TS and $8 \% \mathrm{TS}$, the area of the

4 solar collector decreased by nearly $40 \%$ and $70 \%$, respectively. Although, there was no

5 need to consumer biogas while solar energy was used, the solar heating method was not

6 suitable for districts with low solar radiation in winter, such as Beijing.

7 Scenario 2: biogas boiler. Owing to its concept of no pollution and high efficiency,

8 biogas boiler had been widely applied in China. When biogas boiler was applied, there

9 was no need to input additional energy in the coldest month, however, $95.92 \%, 52.69 \%$

10 and $34.05 \%$ of the produced biogas were consumed for self-heating under OLR of

$113 \% \mathrm{TS}, 5 \% \mathrm{TS}$ and $8 \% \mathrm{TS}$, respectively (Fig.5B). In practice, the heat load can be used

12 for selection of the boiler equipment. One set of 0.2 -ton(8\%TS), 0.3 -ton (5\%TS)and

13 0.5-ton(3\%TS) boiler with heat efficiency of $80 \%$ can be used in this case and the

14 working time is 16 hours per day.

15 Scenario 3: CHP. The CHP, as a promising and cost-effective technology, had been

16 widely developed in European countries. However, it had not been well promoted in

17 China, because of the small capacity and scattered distribution of electricity generation,

18 biogas plants were difficult to create a market-oriented product. However, with the

19 increasing number of large and super-large biogas plant, the installed electricity capacity

20 increased. By 2014, only for the biogas plant treating agricultural waste, the installed

21 electricity capacity is of $177.80 \mathrm{MW}$ and annual electricity production is of 426.8 
1 million kWh (Deng et al., 2017). Thus, the situation will be gradually improved.

2 As can be seen from Fig.5C, for a domestic generator, the amount of power

3 generation and surplus heat recovery by $1 \mathrm{~m}^{3}$ biogas was about $1.8 \mathrm{kWh}$ and $2.4 \mathrm{kWh}$,

4 respectively. The annual electricity production was $6.00 \times 10^{5}(3 \% \mathrm{TS}), 6.71 \times 10^{5}(5 \% \mathrm{TS})$

5 and $5.19 \times 10^{5} \mathrm{kWh}(8 \% \mathrm{TS})$, resulting in a profit of $\$ 5.19 \times 10^{4}-6.71 \times 10^{4}$ (US dollars) at

6 an electricity price of $\$ 0.10 \mathrm{kWh}$ (Zhang et al., 2013). There is also $8.00 \times 10^{5}(3 \% \mathrm{TS})$,

$7 \quad 8.94 \times 10^{5}(5 \% \mathrm{TS})$ and $6.92 \times 10^{5} \mathrm{kWh}(8 \% \mathrm{TS})$ of heat produced annually. The installed

8 power generating capacity of the biogas internal-combustion generator was about 120

$9 \mathrm{kWh}$ at OLR of $3 \%-5 \% \mathrm{TS}$ and $100 \mathrm{kWh}$ at OLR of $8 \% \mathrm{TS}$ with a working time of 16

10 hours per day. The surplus heat that was used for heating the digester with its utilization

11 rate of $70 \%$, so it would not meet the energy demand in winter and supplemental

12 heating energy of $10860.48,3723.02$ and $171.13 \mathrm{MJ}$ should be used under OLR of

$3 \% \mathrm{TS}, 5 \% \mathrm{TS}$ and $8 \% \mathrm{TS}$, respectively.

Sustainability is a vital factor while selecting the heat supply scenarios, which

mainly include economic sustainability and environmental sustainability (Lynch, 2017).

16 In terms of the economic cost, the investment of the biogas boiler, solar collector and

17 electricity generator under 5\%TS was about $\$ 0.63 \times 10^{4}, 1.88 \times 10^{5}$ and $3.14 \times 10^{5}$,

18 respectively. Environmental sustainability has been widely investigated using different

19 assessment methods, such as life cycle assessment, energy, exergy (Rosen, 2018).

20 Specifically in energy system, energy production and utilization should avoid 21 energy-environment conflict (Ali et al., 2018). Considering the environmental 
1 sustainability, the three scenarios are all have less environmental impact in comparison

2 with heating using fossil energy. CHP has great conversion efficiency, thus, can achieve

3 maximum greenhouse gases emission saving. However, the environmental costs caused

4 by electricity generation using fossil fuel were often ignored, and the environmental

5 benefits of electricity generation using biogas were also covered by its economic profit.

6 Therefore the environmental value of electricity generation using biogas is not fully

7 reflected and the technology competitiveness is not fully realized in China. Thereby,

8 considering the energy efficiency and cost, biogas boiler was the best option for the

9 biogas plant with the given breeding scale under moderate OLR. And the rest of the

10 biogas can be used as domestic fuel for pig farms and neighboring households. However,

11 for the CHP, because of the high efficiency and high profit from electricity, so in the

12 long run, it may be a good choice for the biogas plant under high OLR. The solar

13 collector can be used in tropical areas to enhance the heat availability and reduce the

14 energy requirements, simultaneously reduce the collector areas and cost.

15 4. Conclusions

16 In the tested range of lab-scale experiment, the methane yield did not show a linear

17 increase with the increasing of OLR . The OLR of $1.89 \mathrm{gVS} / \mathrm{L} \cdot \mathrm{d}(5 \% \mathrm{TS})$ was optimum

18 for PM anaerobic digestion with HRT of 22 days. In this condition, a rapid start-up, high

19 methane yield and organic matter removal, and stable operation process can be obtained.

20 The OLR also have a significant influence on the mass flow, biogas plant scale, energy

21 requirement and supply for self-heating in the simulated large-scale operation. 
1 Regardless of a lab experiment or biogas plant design, OLR was the important

2 parameter and should be seriously considered.

3 Conflicts of interest

4 The authors declare no conflict of interest.

\section{Acknowledgments}

6 This work was supported by National Natural Science Foundation of China (51506217),

7 National Key Research and Development Program (2018YFD0800803) and open fund

8 of Key Laboratory of Nonpoint Source Pollution Control, Ministry of Agriculture,

9 P.R.China.

\section{References}

11 Abouelenien, F., Fujiwara, W., Namba, Y., Kosseva, M., Nishio, N., Nakashimada, Y., 2010. Improved methane fermentation of chicken manure via ammonia removal by biogas recycle. Bioresour. Technol. 101, 6368-6373.

Ahn, H.K., Smith, M.C., Kondrad, S.L., White, J.W., 2009. Evaluation of biogas production potential by dry anaerobic digestion of switchgrass-animal manure mixtures. Appl. Biochem. Biotechnol. 160, 965-975. environmental sustainability disputes: an evolutional graph model approach. Qual. Quant. https://doi.org/10.1007/s11135-018-0775-9

APHA, 2005. Standard Methods for the Examination of Water and Wastewater, 21th Ed., American Public Health Association/American Water Works Association/ Water 
Environmental Federation, Washington DC, New York, USA.

2

3

4

5

Astals, S., Nolla-Ardèvol, V., Mata-Alvarez, J., 2013. Thermophilic co-digestion of pig manure and crude glycerol: process performance and digestate stability. $\mathrm{J}$. Biotechnol. 166, 97-104.

Bouallagui, H., Rachdi, B., Gannoun, H., Hamdi, M., 2009. Mesophilic and thermophilic anaerobic co-digestion of abattoir wastewater and fruit and vegetable waste in anaerobic sequencing batch reactors. Biodegradation 20, 401-409.

Bonmati, A., Flotats, X., Mateu, L., Campos, E., 2001. Study of thermal hydrolysis as a pretreatment to mesophilic anaerobic digestion of pig slurry. Water Sci. Technol. 44, 109-116.

Calli, B., Mertoglu, B., Inanc, B., Yenigun, O., 2005. Effect of high free ammonia concentrations on the performances of anaerobic bioreactors. Process Biochem. 40, $1285-1292$.

Chae, K.J, Am Jang, Yim, S.K, Kim, I.S., 2008. The effects of digestion temperature and temperature hock on the biogas yields from the mesophilic anaerobic digestion of swine manure. Bioresour. Technol. 99, 1-6.

Chen, L., Zhao, L.X., Ren, C.S., Wang F., 2012. The progress and prospects of rural biogas production in China. Energ. policy 51, 58-63.

Dela-Rubia, M.A., Perez, M., Romero, L.I., Sales, D., 2002. Anaerobic mesophilic and thermophilic municipal sludge digestion. Chem. Biochem. Eng. Q. 16, 119-124.

Deng, L.W., Li, Y., Chen, Z.A., Liu, G.J, Yang, H.N., 2014. Separation of swine slurry 
1 into different concentration fractions and its influence on biogas fermentation.

2 Appl. Energ. 114, 504-511.

Deng, L.W., Liu, Y., Zheng, D., Wang, L., Pu, X.D., Song, L., Wang, Z.Y., Lei, Y.H., Chen, Z.A., Long, Y., 2017. Application and development of biogas technology for the treatment of waste in China. Renew. Sust. Energ. Rev. 70, 845-851.

Dong, F.Q., Lu, J.B., 2013. Using solar energy to enhance biogas production from livestock residue-A case study of the Tongren biogas engineering pig farm in South China. Energ. 57, 759-765.

El-Mashad, H.M., Wilko, K.P., Loon, V., Zeeman, G., 2003. A model of solar energy utilisation in the anaerobic digestion of cattle manure. Biosyst. Eng. 84, 231-238.

Fernandez, J., Perez, M., Romero, L.I., 2008. Effect of substrate concentration on dry mesophilic anaerobic digestion of organic fraction of municipal solid waste (OFMSW). Bioresour. Technol. 99, 6075-6080.

Guo, J B., Dong, R J., Clemens, J., Wang, W., 2013a. Performance evaluation of a completely stirred anaerobic reactor treating pig manure at a low range of mesophilic conditions. Waste Manage. 33, 2219-2224.

Guo, J B., Dong, R J., Clemens, J., Wang, W., 2013b. Thermal modeling of the completely stirred anaerobic reactor treating pig manure at low range of mesophilic conditions. J. Environ. Manage. 127, 18-22.

Hansen, K.H., Angelidaki, I., Ahring, B.K., 1998. Anaerobic digestion of swine manure: Inhibition by ammonia. Water Res. 32, 5-12. 
1 Igoni, A.H., Ayotamuno, M.J., Eze, C.L., Ogaji, S.O.T., Probert, S.D., 2008. Design of

2

3

4 anaerobic digesters for producing biogas from municipal solid-waste. Appl. Energ. $85,430-438$.

Jiang, X Y., Sommer, S.G.., Christensen, K.V., 2011. A review of the biogas industry in China. Energ. Policy 39, 6073-6081.

Jingura, R.M., Kamusoko, R., 2017. Methods for determination of biomethane potential of feedstocks: a review. Biofuel Res. J. 4(2), 573-586.

Li, K., Liu, R.H., Sun, C., 2015a. Comparison of anaerobic digestion characteristics and kinetics of four livestock manures with different substrate concentrations, Bioresour. Technol. 198, 133-140.

Li, K., Liu, R.H., Cui, S.F., Yu, Q., Ma, R.J., 2018. Anaerobic co-digestion of animal manures with corn stover or apple pulp for enhanced biogas production. Renew. Energ. 118, 335-342.

Li, J., Kong, C.X., Duan, Q.W., Luo, T., Mei, Z.L., Lei, Y.H., 2015b. Mass flow and energy balance plus economic analysis of a full-scale biogas plant in the rice-wine-pig system. Bioresour. Technol.193, 62-67.

Liu, C., Yuan, X., Zeng, G., Li, W., Li, J., 2008. Prediction of methane yield at optimum $\mathrm{pH}$ for anaerobic digestion of organic fraction of municipal solid waste. Bioresour. Technol. 99, 882-888.

Liu, J.Y., Chen, Z.X., Li, W.T., 2012. Development and verification of one-dimensional model of steady-state heat transfer for anaerobic fermentation reactor. T. Chinese 
Soc. Agr. Eng. 28, 217-222.

Lynch, J.M., 2017. The Sustainability of Biofuels, in: Love, J., Bryant, J.A. (Eds.),

\section{Biofuels and Bioenergy, John Wiley and Sons Ltd. UK, pp.261-272.}

Ministry of Agriculture of the People's Republic of China, 2011. China Agricultural Statistics. China Agriculture Press, Beijing.

Ni, P., Lyu, T., Sun, H., Dong, R.J., Wu, S.B., 2017. Liquid digestate recycled utilization in anaerobic digestion of pig manure: Effect on methane production, system stability and heavy metal mobilization. Energy 141, 1695-1704.

Pu, X.D., Deng, L.W., Yin, Y., Song, L., Wang, Z.Y., 2010. Economic benefit analysis on large and middle-scale biogas plant with different heating methods. T. Chinese Soc. Agr. Eng. 26, 281-284.

Regueiro, L., Carballa, M., Álvarez, J.A., Lema, J.M., 2012. Enhanced methane production from pig manure anaerobic digestion using fish and biodiesel wastes as co-substrates. Bioresour. Technol. 123, 507-513.

Ren, J.W., Yuan, X.F., Li, J., Ma, X.G., Zhao, Y., Zhu, W.B., Wang, X.F., Cui, Z.J., 2014. Performance and microbial community dynamics in a two-phase anaerobic co-digestion system using cassava dregs and pig manure. Bioresour. Technol. 155, 342-351.

Riau, V., De la Rubia, M.A., Pérez, M., 2010. Temperature-phased anaerobic digestion (TPAD) to obtain class A biosolids: a semi-continuous study. Bioresour. Technol. 101, 2706-2712. 
1 Rosen, M.A., 2018. Environmental sustainability tools in the biofuel industry. Biofuel

2

\section{Res. J. 5(1), 751-752.}

Tada, C., Yang, Y.N., Hanaoka, T., Sonoda, A., Ooi, K., Sawayama, S., 2005. Effect of natural zeolite on methane production for anaerobic digestion of ammonium rich organic sludge. Bioresour. Technol. 96, 459-464.

Tsapekos, K., Kougias, P.G., Treu, L., Campanaro, S., Angelidaki, I., 2017. Process performance and comparative metagenomic analysis during co-digestion of manure and lignocellulosic biomass for biogas production. Appl. Energ. 185,126-135.

Ward, A.J., Hobbs, P.J., Holliman, P.J., Jones, D.L., 2008. Optimization of the anaerobic digestion of agricultural resources. Bioresour. Technol. 99, 7928-7940.

Yang, Y.L., Zhang, P.D., Li, G.Q., 2012. Regional differentiation of biogas industrial development in China. Renew. Sust. Energ. Rev. 16, 6686-6693.

Yenigün, Y., Demirel, B., 2013. Ammonia inhibution in anaerobic digestion: A review. Process Biochem. 48,901-911.

Yu, H., Yuan, J.J., Peng, L., 2015. China’s pig market in 2014 and 2015 prospect review. Guangdong J. Anim. Vet. Sci. 40, 21-23+33.

Zhang, D.J., Duan, N., Tian, H.L., Lin, C., Zhang, Y.L., Liu, Z.D., 2018. Comparing two enhancing methods for improving kitchen waste anaerobic digestion: Bentonite addition and autoclaved de-oiling pretreatment. Process Saf. Environ. 115, 116-124.

Zhang, W.Q., Wei, Q.Y., Wu, S.B., Qi, D.D., Li, W., Zuo, Z., Dong, R.J., 2014. Batch 
1 anaerobic co-digestion of pig manure with dewatered sewage sludge under

2 mesophilic conditions. Appl. Energ.128, 175-183.

3 Zhang, Z.L., Zhang, L., Zhou, Y.L., Chen, J.C., Liang, Y.M., Wei, L., 2013. Pilot-scale

4 operation of enhanced anaerobic digestion of nutrient-deficient municipal sludge

5 by ultrasonic pretreatment and co-digestion of kitchen garbage. J. Environ. Chem.

$6 \quad$ Eng. 1, 73-78.

7 Zhou, J., Yan, G., Wu, Y.Z., 2005. Analysis of solar radiation for Beijing China. Acta $8 \quad$ Energiae Solaris Sinica 26, 712-716. 




Fig.1 The heat demand of the farm-scale biogas plant 


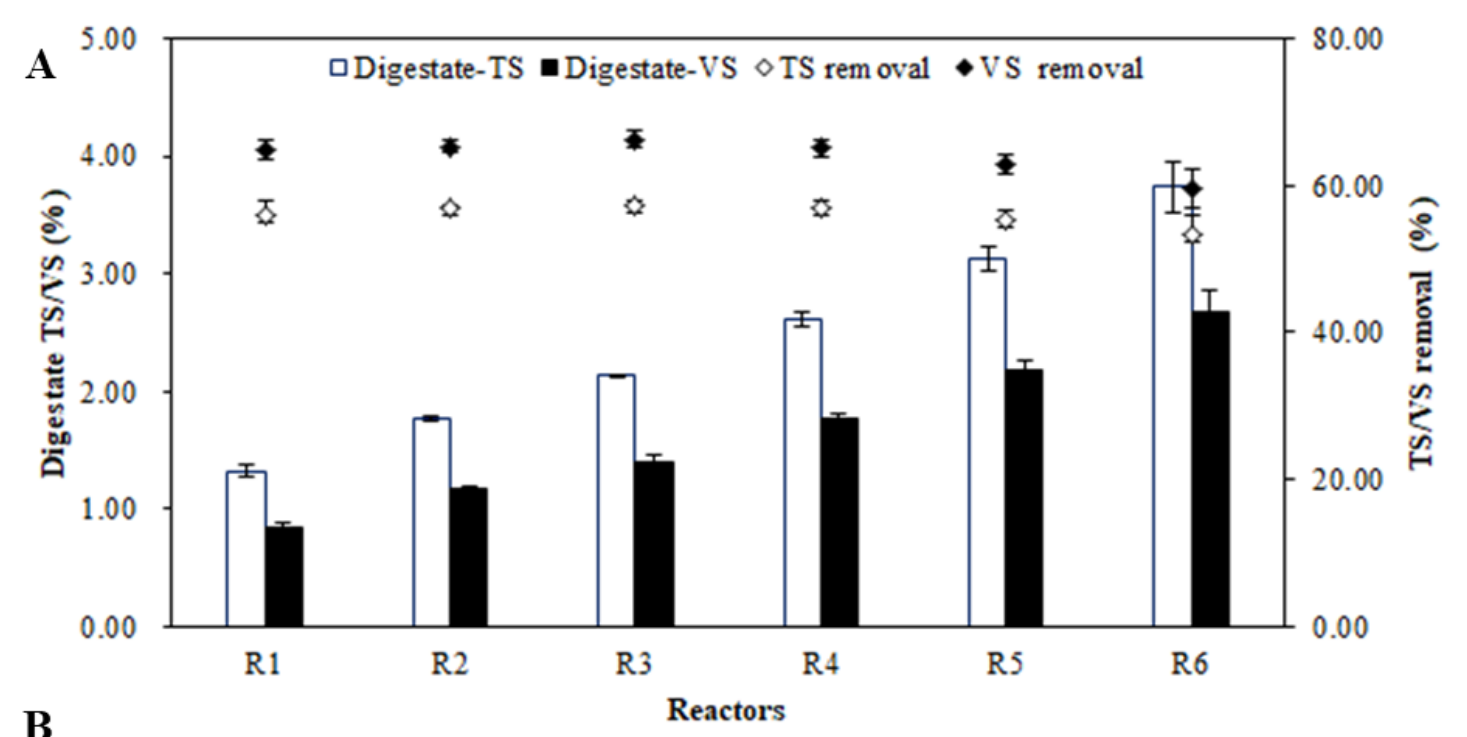

B

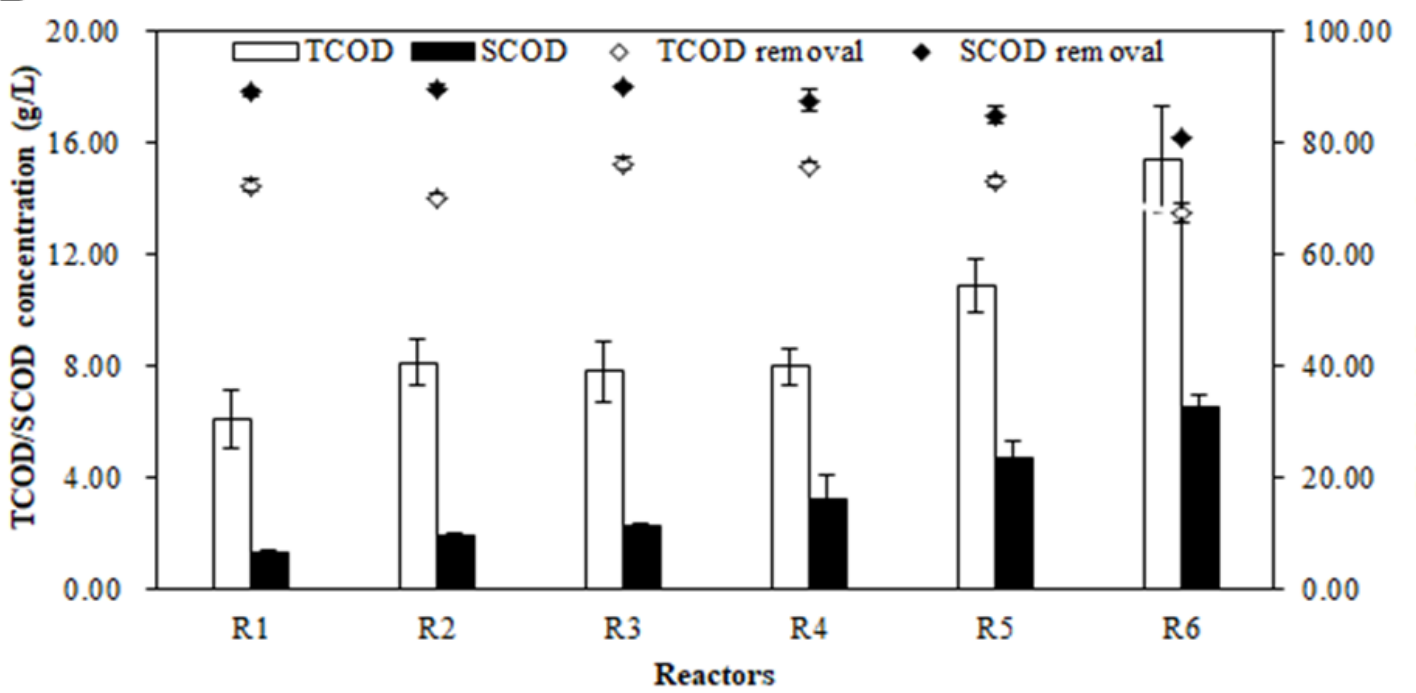

ஓे

Fig.2 Degradation states under different OLRs (A: TS and VS concentration in digestate and removal, B: TCOD and SCOD concentration in digestate and removal) 

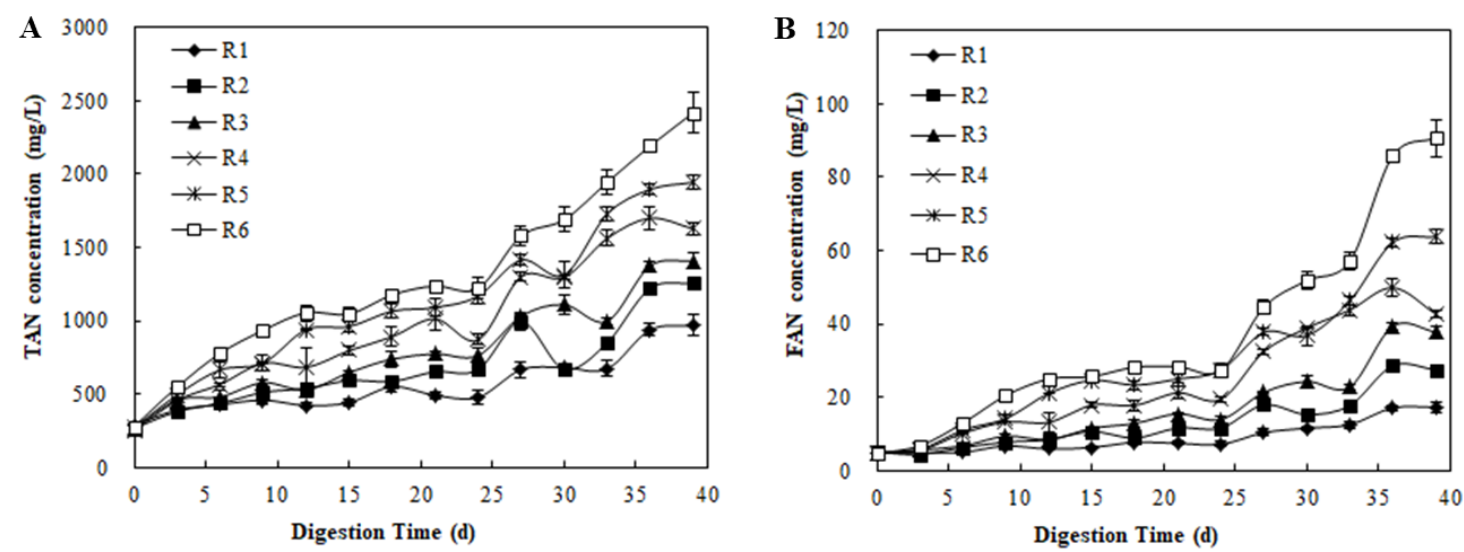

Fig.3 TAN(A) and FAN(B) concentration of digestate with different OLRs 


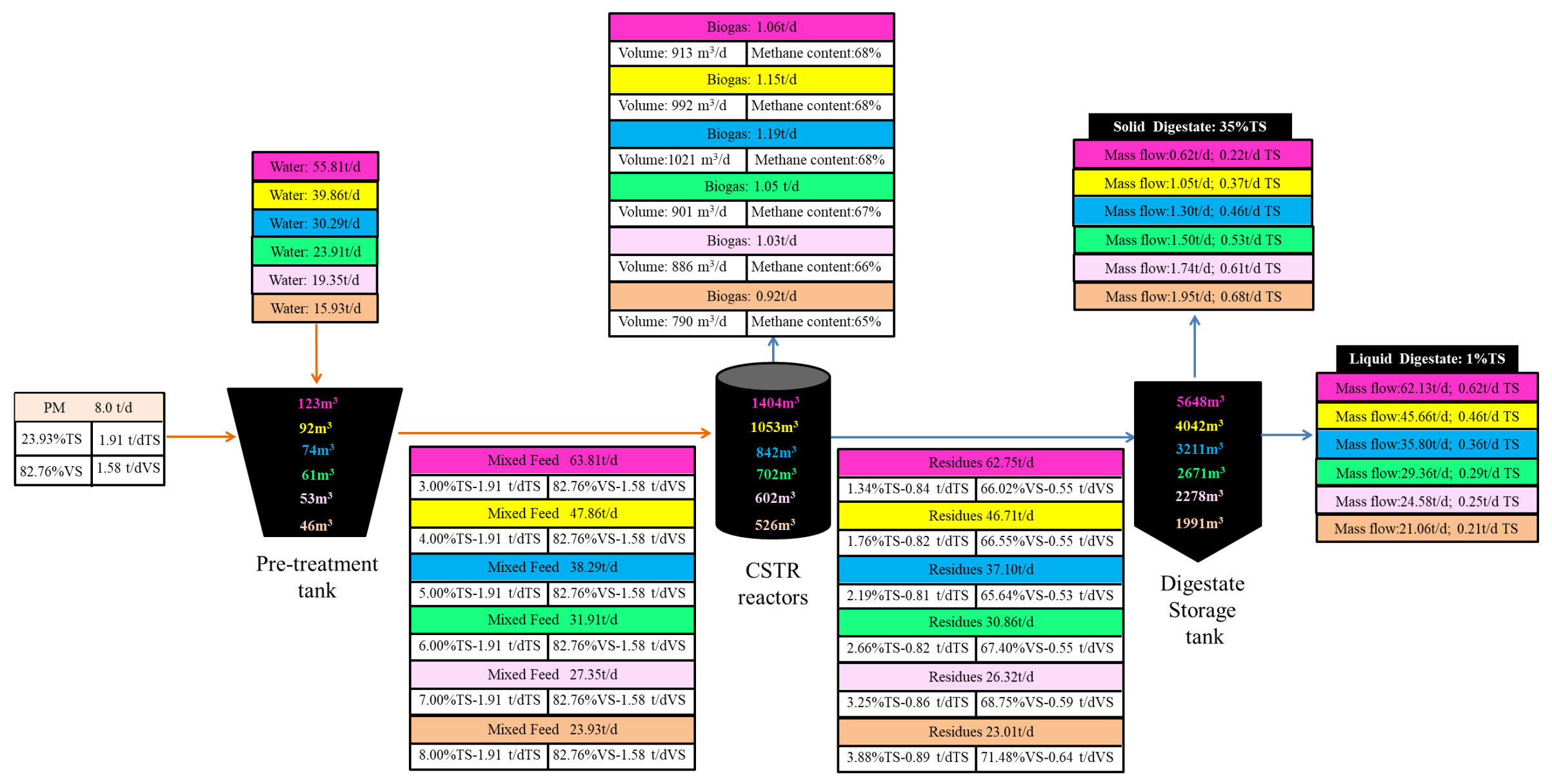

Fig.4 Mass flow and total solid matter flow in the farm-scale biogas plant 

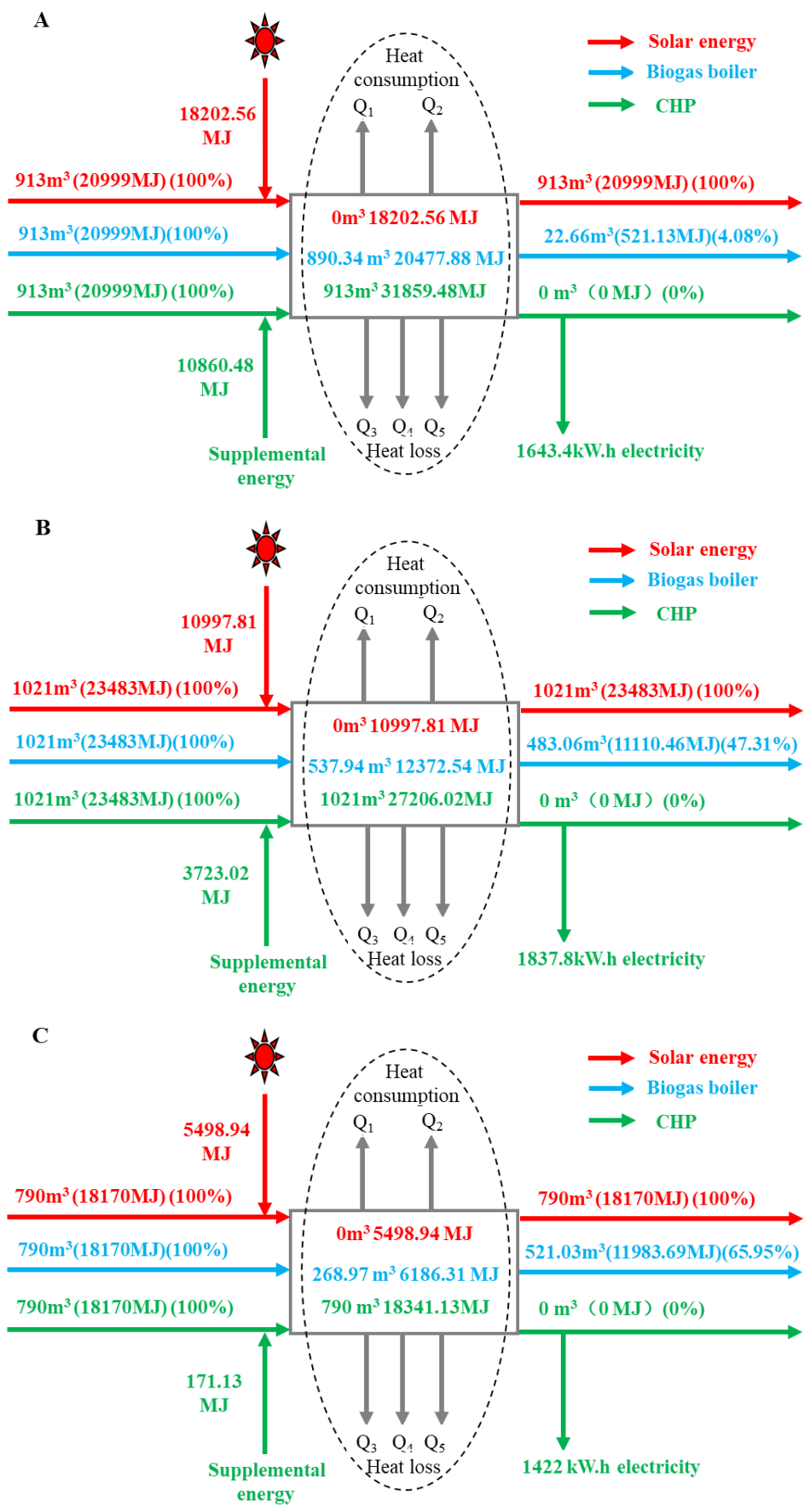

Fig.5 Energy stream diagram with different reactor-heating technology (A-3\%TS;

\section{$\mathrm{B}-5 \% \mathrm{TS} ; \mathrm{C}-8 \% \mathrm{TS})$}


1 Table 1

2 Properties of PM and inoculum in the study.

3

\begin{tabular}{ccc}
\hline Parameter & PM & Inoculum \\
\hline TS $(\%)$ & $23.93 \pm 1.07$ & $0.85 \pm 0.05$ \\
VS (of TS\%) & $82.76 \pm 1.14$ & $70.59 \pm 4.10$ \\
Crude protein (dry basis \%) & $11.38 \pm 0.63$ & - \\
Crude fibers (dry basis\%) & $9.25 \pm 0.33$ & - \\
Crude lipids (dry basis\%) & $11.66 \pm 0.72$ & - \\
Carbohydrates(dry basis\%) & 59.72 & - \\
TKN (g/kg) & $4.36 \pm 1.85$ & - \\
TAN (mg/L) & - & - \\
$\mathrm{C} / \mathrm{N}$ & 10.64 & $7.21 \pm 0.02$ \\
$\mathrm{pH}$ & - & $272.73 \pm 12.30$ \\
\hline
\end{tabular}


Table 2

2 Operation parameters for reactors (R1-R6) in lab condition

\begin{tabular}{|c|c|c|c|c|c|c|}
\hline Parameter & $\mathrm{R} 1$ & $\mathrm{R} 2$ & R3 & R4 & R5 & R6 \\
\hline $\mathrm{TS}(\%)$ & 3 & 4 & 5 & 6 & 7 & 8 \\
\hline OLR gVS/L·d) & 1.13 & 1.51 & 1.89 & 2.27 & 2.65 & 3.03 \\
\hline Feeding $\mathrm{COD}_{\mathrm{t}}(\mathrm{g} / \mathrm{L})$ & $21.94 \pm 1.82$ & $23.74 \pm 0.88$ & $32.85 \pm 2.65$ & $33.14 \pm 0.67$ & $40.65 \pm 1.82$ & $47.3 \pm 2.02$ \\
\hline Feeding $\mathrm{BOD}_{5}(\mathrm{~g} / \mathrm{L})$ & 14.4 & 20.2 & 20.2 & 27.6 & 37.0 & 37.0 \\
\hline $\mathrm{CH}_{4}(\%)$ & $63.45-73.44$ & $63.43-72.42$ & $64.13-72.24$ & $61.63-71.39$ & $61.74-70.64$ & $58.75-70.34$ \\
\hline $\begin{array}{l}\text { Specific methane } \\
\text { yield (mL/gVS) }\end{array}$ & $392.06 \pm 6.41$ & $425.71 \pm 7.49$ & $438.38 \pm 12.81$ & $381.01 \pm 17.45$ & $368.94 \pm 7.20$ & $324.25 \pm 4.60$ \\
\hline $\begin{array}{c}\text { Digestate } \\
\mathrm{BOD}_{5}(\mathrm{~g} / \mathrm{L})\end{array}$ & 2.40 & 2.80 & 3.20 & 5.20 & 6.40 & 9.60 \\
\hline Digestate $\mathrm{pH}$ & $7.19 \pm 0.14$ & $7.27 \pm 0.05$ & $7.32 \pm 0.06$ & $7.39 \pm 0.05$ & $7.42 \pm 0.05$ & $7.45 \pm 0.08$ \\
\hline
\end{tabular}

4 


\section{Table 3}

2 Heat requirement of the farm-scale biogas plant with different OLRs

\begin{tabular}{ccccccccc}
\hline OLR & $\begin{array}{c}\mathrm{Q} 1 \\
(\mathrm{MJ} / \mathrm{d})\end{array}$ & $\begin{array}{c}\mathrm{Q} 2 \\
(\mathrm{MJ} / \mathrm{d})\end{array}$ & $\begin{array}{c}\mathrm{Q} 3 \\
(\mathrm{MJ} / \mathrm{d})\end{array}$ & $\begin{array}{c}\mathrm{Q} 4 \\
(\mathrm{MJ} / \mathrm{d})\end{array}$ & $\begin{array}{c}\mathrm{Q} 5 \\
(\mathrm{MJ} / \mathrm{d})\end{array}$ & $\begin{array}{c}\text { Total heat demand } \\
\sum \mathrm{Q}(\mathrm{MJ} / \mathrm{d})\end{array}$ & $\begin{array}{c}\text { Equivalent } \\
\text { Biogas }\left(\mathrm{m}^{3}\right)\end{array}$ & $\begin{array}{c}\text { Biogas proportion } \\
(\%)\end{array}$ \\
\hline 3\% TS & 10111.33 & 6088.87 & 46.25 & 32.97 & 102.88 & 16382.30 & 712.27 & 78.01 \\
$4 \% \mathrm{TS}$ & 7583.90 & 4566.65 & 50.22 & 35.80 & 96.25 & 12332.82 & 536.21 & 54.05 \\
$5 \% \mathrm{TS}$ & 6067.43 & 3651.59 & 51.72 & 36.87 & 90.43 & 9898.03 & 430.35 & 42.15 \\
$6 \% \mathrm{TS}$ & 3788.78 & 3044.43 & 46.36 & 33.01 & 85.28 & 6997.87 & 304.26 & 33.77 \\
$7 \% \mathrm{TS}$ & 3066.20 & 2610.75 & 44.90 & 31.97 & 78.37 & 5832.19 & 253.57 & 28.62 \\
8\% TS & 2524.27 & 2281.16 & 40.09 & 28.53 & 75.01 & 4949.05 & 215.18 & 27.24 \\
\hline
\end{tabular}

3 Note: the height and diameter of reactor under each TS concentration listed as follows: $12 \mathrm{~m}$ and $13.37 \mathrm{~m}(3 \% \mathrm{TS}) ; 9 \mathrm{~m}$ and $13.37 \mathrm{~m}(4 \% \mathrm{TS})$;

$4 \quad 7.2 \mathrm{~m}$ and $13.37 \mathrm{~m}(5 \% \mathrm{TS}) ; 6 \mathrm{~m}$ and $13.37 \mathrm{~m}(6 \% \mathrm{TS}) ; 5.4 \mathrm{~m}$ and $12.99 \mathrm{~m}(7 \% \mathrm{TS}) ; 4.8 \mathrm{~m}$ and $12.99 \mathrm{~m}(8 \% \mathrm{TS})$ 